\title{
THE IMPACT OF TABLETS DEVICES ON HIGH SCHOOL STUDENTS' COGNITIVE LOAD AND LEARNING
}

\author{
H. Montrieux, T. Schellens \\ Ghent University (BELGIUM)
}

\begin{abstract}
According the multimedia principle, tablet devices are interesting learning tools for education because of their touch interfaces, and the features of influencing tactile, visual and auditory senses. Furthermore, the possibility to adapt the learning concerning students' needs and the ability to provide rich learning content make this tool powerful to support a more constructivist, inquiry-based learning approach. However, little is known about how these tools may affect the learning process. From a cognitive load perspective, authentic inquiry-based learning using technology could be very demanding and could ask a lot from students, because they are characterized by many interacting elements, which consequently leads to a large amount of information that must be processed simultaneously in the limited available working memory. While available research indicates that the cognitive load of students is a good indicator to represent the impact of technology on the conceptual acquisition of the students, an investigation of cognitive load and its' effects on students' learning when using tablet devices is needed. In this light, a quasi-experimental study was set up during a fourweek science course involving 133 students of $9^{\text {th }}$ and $10^{\text {th }}$ grade, and pretest-posttest differences were measured. Next to an achievement test, cognitive load was measured by using the NASA-TLX measurement. Students were randomly assigned to two conditions: 1) tasks on tablets with adapted learning material according to the students' needs, 2) tasks on tablets without adaptive learning material. The adapted learning material was based on the theoretical framework of Tomlinson. Students in both the conditions used an inquiry-based tablet application. The results show that students gained knowledge after the intervention, and especially students of the experimental condition outperformed students who worked without adaptive material on their tablets. In addition, a paired-t-test shows that the cognitive load was significantly lower in the posttest compared with the cognitive load measured in the pretest. Furthermore, condition has an impact on students' cognitive load. These results show that tablets can be introduced to reduce the cognitive load. However, while working with adapted material on tablets can meet students' needs, one should be cautious with increasing the cognitive load. To conclude, this research confirms the importance to take cognitive load into account, because of its significant impact on students' learning.
\end{abstract}

Keywords: tablet devices, cognitive load, secondary education, prior-knowledge

\section{INTRODUCTION}

The growing diversity necessitates the development and use of diverse teaching strategies to respond to the individual needs of students. In this light, Tomlinson [1] states that teachers can meet the diversity of students through an adaption of content (what is learned), an adaption of process (how the content is mastered by the student), an adaption of the product (how the learning is observed and evaluated), or by adaption of the learning environment. According to the adaption of the learning environment, technology can be added to facilitate differentiation, because it allows opportunities to provide students with adaptive content tailored to their needs [2]. However, despite the awareness of the need for differentiation [3,4], specific research on how differentiated instruction can be implemented and supported by technology is still limited.

Recently, a tool that finds its way into education is the tablet device. This tool can be considered as an interesting tool for education because of the touch interfaces, and the features of influencing tactile, visual and auditory senses [5]. While tablets offer new possibilities to the learning environment because next to its instrumental value - by its lightness and serving as an all-in-one-device - it can foster differentiated learning [6]. Moreover, based on the multimedia principle [7], tablets are appropriate tools to learn both from words and pictures simultaneously. However, because tablets involve a high device-user exchange, it is increasingly important to question how this technology interacts with the cognitive structure. There is little examination of how users interactions with these technological objects affect the learning process [5]. 
From a cognitive load perspective, authentic inquiry-based learning using technology could be very demanding and could ask a lot from students because they are characterized by many interacting elements, which consequently leads to a large amount of information that must be processed simultaneously in the limited available working memory [8]. While available research indicates that the cognitive load of students is a good indicator to represent the impact of technology on the conceptual acquisition of the students [9]. Therefore, an investigation of cognitive load and its' effects on students' learning when using tablet devices is needed. The cognitive load theory (CLT) focuses on the human cognitive architecture that refers to the structure of our mind, which consists of two main components. The working memory entails a limited capacity to process new unorganised information, and transfers learned information into schemata for storage in the unlimited long-term memory [10]. The CLT provides an appropriate framework for optimising learning by designing instructional strategies that takes the limited working memory into account [11]. Such environments can enhance the cognitive load of learners because besides its' complexity of the task itself, it also entails a technical complexity to tackle [12]. When learning using tablets, providing differentiated content is interesting because it highlights how individual differences in learners' cognitive ability influence cognitive overload [5]. Moreover, available research that focuses on cognitive load revealed that students' prior-knowledge is the most important learner characteristic that influences the learning process [13]. When learners do not have relevant knowledge, they have to deal with much new information, which can lead to an overload in the working memory, or cognitive overload. In addition, the expertise-reversal effect indicates that while some instructional strategies are effective for novices, they can have rather negative consequences for more experienced learners [14]. Thus, based on this information, tailored adaptive learning material can help learners to control the cognitive load, to maximize learning. In line with the theoretical framework and building on the aforementioned gaps, the next research questions drove this study:

- RQ1) What is the impact of using tablets towards students' cognitive load and learning?

- $\quad$ RQ2) Is there an impact of condition on cognitive load and learning?

\section{METHODOLOGY}

A quasi-experimental study was set up during a four-week science course involving 133 students of $9^{\text {th }}$ and $10^{\text {th }}$ grade. By using a pretest and a posttest measurement, differences between the regular science course and the science course with tablets are compared. Next to an achievement test (max. score 10), cognitive load was measured by using a modified version of the NASA-TLX measurement of Hart \& Staveland [15]. The multi-dimensional NASA-TLX measures workload via six subscales, each associated with a different source of workload. Each of the six cognitive load items was rated on a scale ranging from 0 (low cognitive load) to 10 (high cognitive load). See Table 1 for the corresponding items:

Table 1. NASA-TLX measurement

\begin{tabular}{l|l}
\hline \hline Subscales & \multicolumn{1}{c}{ Corresponding item } \\
\hline Mental demand & How much mental activity was required? \\
\hline Physical demand & How much physical activity was required? \\
\hline Temporal demand & $\begin{array}{l}\text { How much time pressure did you feel due to the pace at } \\
\text { which the tasks occurred? }\end{array}$ \\
\hline Performance & How successful were you in performing the task? \\
\hline Effort & How hard did you have to work to accomplish the task? \\
\hline Frustration & $\begin{array}{l}\text { How irritated, stressed, and annoyed did you feel during } \\
\text { the task? }\end{array}$ \\
\hline \hline
\end{tabular}


In a quasi-experimental design, students were randomly assigned to two conditions: an experimental condition with tasks on tablets and adapted learning material according to the students' needs versus the control condition whereas students worked also on tablets but without the adapted learning material. The adapted learning material was based on the theoretical framework of Tomlinson. According to this framework, the learning material was differentiated among content, process, and product according to student's readiness, interests, and learning profiles [1]. Moreover, concerning content, students completed adapted exercises according to their readiness. Concerning the process, students could choose the way that they wanted to learn the material. They could choose between watching an instructional movie, reading a text, and manipulating objects as different ways of learning the same content. Concerning product, students were free to choose between different applications (Mindmeister, explain everything, Prezi, or PowerPoint) to prepare their presentation of a particular illicit drug.

Students in the two conditions used an inquiry-based tablet application concerning drug prevention (High!). In this educational package, students were offered inquiry tasks concerning the different illicit drugs and the harmful impact of these drugs on the brain. Because this topic entails an amount of abstractness, using tablets (scanning QR-codes, watching movies, manipulating objects, etc.) to visualize the content is appropriate. In addition to the digital learning environment, each student received an individual paper notebook and an overview of the exercises. In this environment, miniinquiry tasks based on the inquiry steps of Bruce and Davidson [16] were developed. The steps implemented included: 1) building a research question, 2) a hypothesis, 3) collecting data, 4) making a data-analysis, 5) discussion, and 6) reflection.

\section{RESULTS}

\subsection{RQ1: Impact of the tablet intervention on cognitive load and learning}

The intervention has an impact on students' learning $(t(122)=12.60, p=.000)$. Moreover, students scored higher in the posttest $(M=6.00, S D=2.05)$ compared to the pretest $(M=3.56, S D=2.13)$. In addition, paired samples t-tests were conducted to compare the means of the six different cognitive load constructs before and after the intervention, thus comparing the cognitive load as experienced in the regular science course with the science course whereas tablets were integrated. As described in Table 2, t-test results show that there is a significant decrease of the constructs mental demand and effort. Moreover, the use of tablets during the science course has decreased students' feeling that learning science is less mentally demanding compared with the course before the tablet implementation. In addition, students reported that by using tablets, they perceived to do less effort to acquire the needed knowledge.

Table 2. Descriptives and paired t-tests

\begin{tabular}{l|c|c|c}
\hline \hline & Pre $M(S D)$ & Post $M(S D)$ & $t(96)$ \\
\hline Mental demand & $5.00(2.23)$ & $4.03(2.40)$ & $3.19^{*}$ \\
\hline Physical demand & $2.95(2.38)$ & $2.73(2.75)$ & .74 \\
\hline Temporal demand & $4.26(2.61)$ & $4.04(2.91)$ & .63 \\
\hline Performance & $6.04(1.70)$ & $6.05(2.22)$ & -.04 \\
\hline Effort & $6.56(1.95)$ & $5.40(2.03)$ & $4.28^{* *}$ \\
\hline Frustration & $5.15(2.79)$ & $4.44(3.03)$ & 1.84 \\
\hline \hline
\end{tabular}

${ }^{*} p<.05,{ }^{* *} p<.001$ 


\subsection{RQ2: Impact of condition on cognitive load and learning}

An univariate analysis with the learners' pre-achievement test as covariate shows that condition is significant $(F(1,120)=11.15, p=.001)$. Moreover, students of the experimental condition performed better $(M=6.54, S D=.23)$ compared to students of the control condition $(M=5.37, S D=.25)$. In addition, the descriptives (see Table 3) show interesting results, such as the fact that students of the experimental condition reported that working with adapted learning material has increased the physical demands and required more effort to accomplish the tasks, compared to students of the control condition. In addition, students in the control condition without the adaptive material reported a higher level of frustration and stated that the task on the tablet was more mentally demanding. However, based on univariate analysis of variance, only the construct performance is significant. Students of the experimental condition reported to be more successful to learn compared to the students of the control condition.

Table 3. Condition and cognitive load

\begin{tabular}{|c|c|c|c|}
\hline & Condition & $M(S D)$ & $p$-value \\
\hline \multirow[t]{2}{*}{ Mental demand } & Experimental & $3.85(.32)$ & \multirow[t]{2}{*}{$>.05$} \\
\hline & Control & $4.13(.36)$ & \\
\hline \multirow[t]{2}{*}{ Physical demand } & Experimental & $2.84(.37)$ & \multirow[t]{2}{*}{$>.05$} \\
\hline & Control & $2.51(.41)$ & \\
\hline \multirow{2}{*}{$\begin{array}{l}\text { Temporal } \\
\text { demand }\end{array}$} & Experimental & $3.95(.39)$ & \multirow[t]{2}{*}{$>.05$} \\
\hline & Control & $3.98(.44)$ & \\
\hline \multirow[t]{2}{*}{ Performance } & Experimental & $6.53(.29)$ & \multirow[t]{2}{*}{.008} \\
\hline & Control & $5.36(.32)$ & \\
\hline \multirow[t]{2}{*}{ Effort } & Experimental & $5.60(.28)$ & \multirow[t]{2}{*}{$>.05$} \\
\hline & Control & $5.09(.31)$ & \\
\hline \multirow[t]{2}{*}{ Frustration } & Experimental & $3.87(.40)$ & \multirow[t]{2}{*}{$>.05$} \\
\hline & Control & $4.96(.45)$ & \\
\hline
\end{tabular}

\section{CONCLUSIONS}

The touch interfaces, and the features of influencing tactile, visual and auditory senses [5], make the tablet an appropriate tool to support a more constructivist, inquiry-based learning approach [4]. However, little is known about how these tools may affect the learning process. In addition, from a cognitive load perspective, inquiry-based learning using technology could be very demanding and could ask a lot from students because they are characterized by many interacting elements, which consequently leads to a large amount of information that must be processed simultaneously in the limited available working memory [8]. Informed by the cognitive load theory [10], this study investigated the impact of cognitive load on learning while using tablet devices. In a quasiexperimental design, students were randomly assigned to two conditions: 1) the experimental condition with tasks on tablets with adapted learning material according to the students' needs, 2) the control condition with tasks on tablets but without adapted learning material. Pretest and posttest measurements were investigated among 133 students of $9^{\text {th }}$ and $10^{\text {th }}$ grade. Next to an achievement test, cognitive load was measured by using the NASA-TLX measurement [15].

Results from the first research question show that besides students' knowledge tests were significant higher in the posttest compared to the pretest (that is, students acquired knowledge), two constructs of cognitive load (e.g., mental demand and effort) were significantly lower in the posttest compared with 
the cognitive load measured in the pretest. This means that students perceived a lower cognitive load when using tablets. This result highlights that the use of tablet technology made abstract content more visible and touchable [5], and following the multimedia principle of Mayer [7], a lower cognitive load can be related to the way that by learning words and pictures simultaneously, this results in a lower need of cognitive capacity, and thus a lower cognitive load. When regarding the second research question, the condition plays an important role towards the gained knowledge. Moreover, students of the experimental condition performed better compared to students of the control condition. This finding shows that tablet devices, by its affordances, can indeed foster differentiated learning [6]. Furthermore, while descriptives show that students who worked with adaptive material reported that the tablet task was physically demanding and they had to invest more effort, while students without adaptive material tended to be more frustrated and reported an increased mentally demand, only the construct 'performance' was significant, indicating that students without adaptive material experienced the lowest level of success during the task. The result of this last research question shows the importance of adapting the learning material to meet individual students' cognitive capabilities, and highlights how individual differences in learners' cognitive ability influence cognitive overload [5]. The lower results in the control condition can be related towards the fact that when learners do not have relevant knowledge, they have to deal with much new information, which can lead to an overload in the working memory, or cognitive overload [13]. In general, these results show that tablets can be introduced to reduce the cognitive load. However, based on the descriptives, one should be cautious with increasing the cognitive load by providing adaptive material, because it may increase the (mental) effort that students had to invest to complete the tasks.

Some limitations and venues for further research can be discussed. First, due to this large-scale study, cognitive load was measured only before and after the intervention, and this by using a subjective measurement tool. Because a retrospective, subjective-based measurement has been used, questions can be raised concerning the validity of the measurement of cognitive load. In further research, direct and objective measurements should be used, such as eye-tracking measurements. Eye-tracking tools could measure the cognitive capacity of students real-time, while they are performing the task. This will make the measurement of cognitive load more accurate and valid. Secondly, while this study was a first step in measuring the relation between cognitive load and students' achievement at the end of a tablet intervention, only an indication of the global cognitive load is measured. Further research should focus on a single specific task on the tablet, or conducting repeated measures of the specific cognitive load during each task. To conclude, because of the rapid introduction of tablet devices in education, more research is needed in order to investigate the interactive nature of tablets in relation with cognitive load and thus students' achievement, in order to set up specific guidelines concerning the development of learning material on these specific tools.

\section{REFERENCES}

[1] C.A. Tomlinson, "The Differentiated Classroom : Responding to the Needs of All Learners", ASCD: USA, 2014.

[2] M. Sarrab, L. Elgamel, \& H. Aldabbas, "Mobile Learning (M-Learning) and Educational Environments", International Journal of Distributed and Parallel Systems, vol. 3, no. 4, pp. 31 38, 2012.

[3] M.J. Hannafin, J.R. Hill, S.M. Land, \& E. Lee, "Student-Centered, Open Learning Environments: Research, Theory, and Practice", In Handbook of Research on Educational Communications and Technology, pp. 641-651; New York: Springer, 2014.

[4] P. Konstantinou-Katzi, E. Tsolaki, M. Meletiou-Mavrotheris, \& M. Koutselini, "Differentiation of teaching and learning mathematics: an action research study in tertiary education", International Journal of Mathematical Education in Science \& Technology, vol. 44, pp. 332-349, 2013.

[5] R. McEwen, \& A. Dubé, "Engaging or distracting: children's tablet computer use in education", Educational Technology \& Society, vol. 18, no. 4, pp.9-23, 2015.

[6] K. Melhuish, \& G. Falloon, "Looking to the future: M-learning with the iPad", Computers in New Zealand Schools, vol. 22, no. 3, pp. 1-16, 2010.

[7] R.E. Mayer, Multimedia learning. New York: Cambridge University Press, 2001. 
[8] J. van Merriënboer \& J. Sweller, "Cognitive load theory and complex learning: recent developments and future directions", Educational psychology review, vol.17, no. 2, pp.147-177, 2005.

[9] G.J. Hwang, P.H.Wu, Y.Y. Zhuang, \& Y.M. Huang, "Effects of the inquiry-based mobile learning model on the cognitive load and learning achievement of students", Interactive Learning Environments, vol. 21, no. 4, pp. 338-354, 2013.

[10] J. Sweller, Human cognitive architecture. In. Handbook of research for educational communications and technology (M. Spector et al., Eds.), pp. 369-383, New York: Lawrence Erlbaum Associates, 2008.

[11] F. Paas, T. van Gog, J. Sweller, "Cognitive Load Theory: New Conceptualizations, Specifications, and Integrated Research Perspectives", Educational Psychology Review, vol. 22, no.2, pp. 115-121, 2010.

[12] C.M. Van Mierlo, H. Jarodzka, F. Kirschner, \& P.A. Kirschner, Cognitive load theory in elearning. In Encyclopedia of cyber behavior, (Z. Yan, Ed.), pp. 1178-1211, Hershey, PA: IGI Global, 2012.

[13] S. Kalyuga, "Managing cognitive load in adaptive ICT-based learning", Systemics, cybernetics, and informatics, vol. 7, no.5, pp. 16-21, 2009.

[14] S. Kaluyga, "Expertise reversal effect and its implications for learner-tailored instruction", Educational Psychology Review, vol. 9, pp. 509-539, 2007.

[15] S.G. Hart, L.E. Staveland, Lowell, "Development of NASA-TLX (Task Load Index): Results of Empirical and Theoretical Research", Advances in Psychology, vol. 52, pp. 139-183, 1988.

[16] B.C. Bruce, \& J.D. Davidson, "An inquiry model for literacy across the curriculum", Journal of Curriculum Studies, vol. 28, no. 3, pp. 281-300, 1996. 